Jansen and Roche., Speakers bureau: Consultation fees/participation in company sponsored speaker's bureau from Pfizer, Lilly, Sobi, Celgene, Novartis, Roche and Sanofi., Ricardo Blanco Grant/research support from: Abbvie, MSD, and Roche, Consultant for: Abbvie, Pfizer, Roche, BristolMyers, Janssen, Speakers bureau: Abbvie, Pfizer, Roche, Bristol-Myers, Janssen

DOI: 10.1136/annrheumdis-2019-eular.3623

\section{THU0314 OUTCOMES OF PATIENTS TREATED WITH TOCILIZUMAB OR ABATACEPT AS STEROID-SPARING AGENTS WITH GIANT CELL ARTERITIS}

Daniela Rossi, Irene Cecchi, Elena Rubini, Massimo Radin, Savino Sciascia, Dario Roccatello. University of Turin, Turin, Italy

Background: Giant cell arteritis (GCA) is a common form of systemic vasculitis. The current mainstay of GCA management is glucocorticoid (GC) therapy. Recently, at least 2 biological therapies [tocilizumab (TCZ)

Abstract THU0314 -Table 1.

Table 1. Characteristics of the patients included in the study

\begin{tabular}{|c|c|c|}
\hline & $\begin{array}{l}\text { Total number of } \\
\text { patients (33) }\end{array}$ & $\%$ \\
\hline \multicolumn{3}{|l|}{ Demographic characteristics } \\
\hline Female/Male & $21 / 12$ & \\
\hline Age (years) (mean, SD) & $73.6 \pm 8.7$ & \\
\hline \multicolumn{3}{|l|}{ Clinical characteristics at the onset of GCA } \\
\hline Fever $(n)$ & 12 & 36.4 \\
\hline Fatigue (n) & 18 & 54.5 \\
\hline Headache (n) & 28 & 84.8 \\
\hline Scalp tenderness $(n)$ & 8 & 24.2 \\
\hline Jaw claudication $(n)$ & 15 & 45.4 \\
\hline Vision loss (n) & 16 & 48.5 \\
\hline PMR (n) & 11 & 33.3 \\
\hline \multicolumn{3}{|l|}{ Diagnosis } \\
\hline Biopsy proven & $27 / 32$ & 84.4 \\
\hline PET positivity & $12 / 29$ & 41.4 \\
\hline Eco-color-doppler positivity & $30 / 31$ & 97 \\
\hline \multicolumn{3}{|l|}{ GC therapy } \\
\hline Previous methylprednisolone pulses (n) & 7 & 21.2 \\
\hline Oralprednisone (n) & 33 & 100 \\
\hline Dose of oral prednisone (mg/day) (mean, SD) & $49.7 \pm 15.1$ & \\
\hline \multicolumn{3}{|l|}{ Previous immunosuppressive therapies } \\
\hline Methotrexate (n) & 11 & 33.3 \\
\hline Mean dose (mg/week) (mean, SD) & $15.6 \pm 1.7$ & \\
\hline Mycophenolate $(n)$ & 6 & 18.1 \\
\hline Mean dose ( $\mathrm{g} /$ day) (mean, $\mathrm{SD})$ & $2.2 \pm 0.4$ & \\
\hline
\end{tabular}

and abatacept $(A B A)$ ] have been proven to be effective in the management of CGA in randomized controlled trials. Nevertheless, their use as steroid sparing agents might need further investigation.

Objectives: We aimed to investigate the steroid-sparing effect of biological therapies, namely TCZ and ABA, in a cohort of GCA patients when compared to standard GC treatment.

Methods: We retrospectively collected data from GCA patients who attended the S.G. Bosco Hospital, Turin, Italy, who were treated with TCZ, both intravenous (IV) and subcutaneous (SC), and/or ABA SC (8 $\mathrm{mg} / \mathrm{kg} / \mathrm{month}, 162 \mathrm{mg} /$ week, and $125 \mathrm{mg} /$ week respectively). These therapies were prescribed as first line agents or as second line when patients were refractory/intolerant/contraindicated to standard immunosuppressive therapies. Complete response to the treatment was define as a clinical and serological remission after 12 months of therapy; partial response was defined as clinical or serological remission after 12 months of therapy.

Results: This retrospective study included 33 GCA patients [mean age 74 (range $85-57$ ), females $63 \%$, mean follow-up from GCA diagnosis 44.4 \pm 33.5 months). Table 1 resumes the characteristics of the GCA patients included in the study.

Twenty-eight patients out of $33(85 \%)$ received one biologic agent. Five patients (15\%) needed a therapeutic switch (one patient from TCZ to $\mathrm{ABA}$, and 4 patients from $\mathrm{ABA}$ to $\mathrm{TCZ})$. Patients were treated as follow: 9 with TCZ IV, 11 with TCZ SC, and 18 with ABA. Among the TCZ IV group, all patients experienced a response (57\% complete response, and $43 \%$ partial response). Among the TCZ SC group, $83 \%$ experienced a response $(67 \%$ complete response, and $16 \%$ partial response). Among the ABA group, $86 \%$ experienced a response (36\% complete response and $50 \%$ partial response). After 12 months of therapy, $100 \%$ of patients in TCZ groups, both IV and SC, and $64.2 \%$ of ABA group were treated with low doses of oral prednisone ( $\leq 7.5 \mathrm{mg} /$ day) as maintenance. We noticed a significant reduction of inflammatory parameters [C-reactive protein (CRP) and erythrocyte sedimentation rate (ESR)] after 12 months of therapy with TCZ [TCZ IV group: mean baseline CRP (mg/dl) 1.9 \pm 2.3 , mean CRP after 12 months of therapy $0,3 \pm 0.2$; mean baseline ESR $(\mathrm{mm} / \mathrm{h})$ 58.1 \pm 25.6 , mean ESR after 12 months $9.5 \pm 4.2$; TCZ SC group: mean baseline CRP 4.5 \pm 3.8 , mean CRP after 12 months $0.2 \pm 0.2$; mean baseline ESR 51.9 \pm 27 , mean ESR after 12 months $6.5 \pm 6]$. When compared to standard GC regimen [1], in patients treated with TCZ, both IV and SC, we estimated a median steroid-sparing effect quantifiable in 30 $\mathrm{mg} /$ daily in the first month and an overall steroid-sparing effect of $15 \mathrm{mg} /$ daily when assessed in 12 months.

Conclusion: This retrospective study confirms the efficacy of biologica therapies in the management of CGA. Besides, in our experience TCZ allowed a significant reduction of GCs use, especially in the first month of therapy, when compared to standard GCs based regimens.

\section{REFERENCE:}

[1] Dasgupta B, et al. BSR and BHPR Standards, Guidelines and Audit Working Group. BSR and BHPR guidelines for the management of giant cell arteritis. Rheumatology. 2010 Aug;49(8):1594-7.

Disclosure of Interests: None declared

DOI: 10.1136/annrheumdis-2019-eular.4807

\section{THU0315 SEVERITY AND RESPONSE TO INDUCTION THERAPY IN NEW AND RELAPSING ANCA ASSOCIATED VASCULITIS PATIENTS - REAL WORLD PRACTICE DATA}

Peter Rutherford, Dieter Götte. Vifor Pharma, Medical, Zurich, Switzerland

Background: ANCA-associated vasculitis (AAV) presents clinically with variable severity of disease and current clinical guidelines give varying advice on initial treatment to induce remission. Achieving remission quickly is important to gain disease control and avoid cumulative organ damage from treatment related adverse events.

Objectives: This study examined real world practice of AAV treatment in Europe to understand the AAV severity spectrum and the response to therapy over 12 months.

Methods: 929 incident and 268 relapsing EU AAV patients receiving care from 399 physicians were studied. Patients were referred between 201417 and data collected retrospectively at baseline and 1, 3, 6 and 12 months following induction therapy. Birmingham Vasculitis Activity Score (BVAS) was collected in only $12 \%$ of patients and severity was defined as mild (localized disease with no systemic symptoms), moderate (Mod, systemic disease with lung and/or kidney involvement) or systemic (rap idly progressive systemic disease with lung and/or kidney involvement). Results: AAV disease severity varied in both incident (mild $12.2 \%$, moderate $54.3 \%$, severe $33.6 \%$ ) and relapsing (corresponding values 9.7, 64.6 and 25.7) patients at start of treatment. Comorbidity at time of

Abstract THU0315 -Table 1

\begin{tabular}{|c|c|c|c|c|c|c|c|c|c|c|c|c|}
\hline & \multicolumn{3}{|c|}{1 month } & \multicolumn{3}{|c|}{3 months } & \multicolumn{3}{|c|}{6 months } & \multicolumn{3}{|c|}{12 months } \\
\hline & Mild & Mod & Severe & Mild & Mod & Severe & Mild & Mod & Severe & Mild & Mod & Severe \\
\hline Full & 55.3 & 21.0 & 13.5 & 59.4 & 47.2 & 28.7 & 82.6 & 64.7 & 45.0 & 82.8 & 70.7 & 53.5 \\
\hline Partial & 42.2 & 74.1 & 67.9 & 38.4 & 48.8 & 56.8 & 14.5 & 32.0 & 40.6 & 17.2 & 26.0 & 35.7 \\
\hline No & 2.5 & 4.9 & 18.6 & 2.2 & 4.0 & 14.5 & 2.9 & 3.3 & 14.4 & 0 & 3.3 & 10.8 \\
\hline
\end{tabular}


induction therapy was more common in severe patients $(71.8 \%$ of patients having at least one comorbidity) compared to mild patients (55.1\%). Since BVAS was not measured routinely, clinical response was categorized as full (no vasculitis activity and GC taper on track), partial (reduction in vasculitis activity and major organ damage arrested) and no response (no improvement in vasculitis). Clinical response is presented below (\% patients) for combination of incident and relapsing patients demonstrating that response varied with many patients having slow and/or incomplete response. Response varied by severity of the disease when induction therapy commenced.

Conclusion: Incident and relapsing AAV patients have variable disease severity at the time of induction therapy. Response to induction therapy is with few exceptions better in patients with milder AAV but overall many patients are slow to respond or have only a partial response to current induction therapy.

Acknowledgement: This work was supported by Vifor Pharma

Disclosure of Interests: Peter Rutherford Employee of: Vifor Pharma, Dieter Götte Employee of: Vifor Pharma

DOI: 10.1136/annrheumdis-2019-eular.1959

\section{THU0316 PROTEINASE-3 REGULATING MICRO-RNA IN GRANULOMATOSIS WITH POLYANGIITIS}

Susanne Schinke ${ }^{1}$, Nick Reichard ${ }^{2}$, Barbara Russo $^{3}$, Antje Müller $^{2}$, Martin Laudien ${ }^{4}$, Robert Häsler ${ }^{5}$, Gabriela Riemekasten ${ }^{1}$, Peter Lamprecht ${ }^{1}$. ${ }^{1}$ University Lübeck, UKSH Campus Lübeck, Rheumatology and Clinical Immunology, Lübeck, Germany; ${ }^{2}$ University Lübeck, Lübeck, Germany; ${ }^{3}$ University Hospital and School of Medecine, Immunology and Allergy, Geneva, Switzerland; ${ }^{4}$ UKSH Campus Kiel, HNO-Klinik, Kiel, Germany; ${ }^{5}$ Christian-Albrechts-University Kiel, Clinical Molecular Biology, Kiel, Germany

Background: Dysregulated miRNA expression profiles have been described in diverse chronic inflammatory diseases. We previously did a microarray screening of 847 miRNAs in nasal tissue from GPA patients and we found a disease associated alteration of miRNA expression compared to healthy controls $(\mathrm{HC})$ and chronic rhinosinusitis (CRS).

Objectives: In order to identify new miRNA targets of potential pathophysiological relevance in GPA, we validated dysregulated miRNAs by qPCR
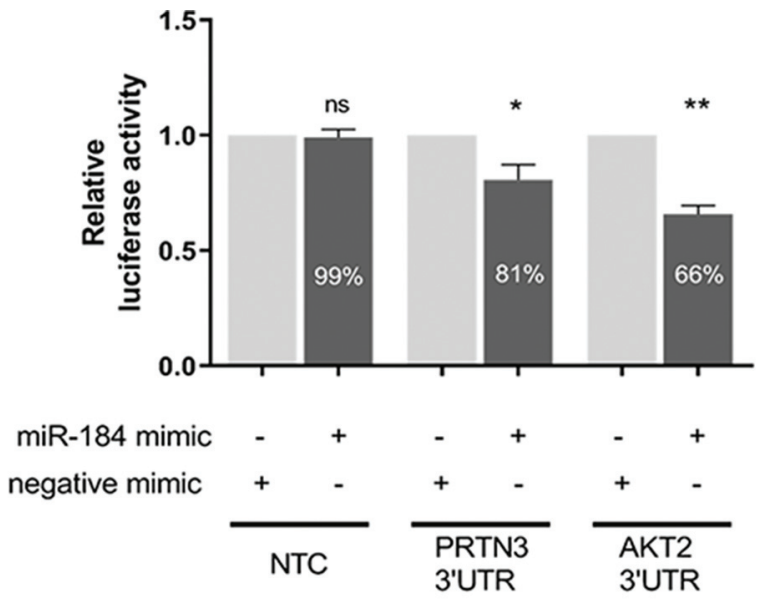

Fig. 1: Dual-luciferase reporter assays showing a decrease in luciferase activity when fused to the 3'UTR of PRTN3 3 and co-transfected with microRNA-184 mimic. No reduction can be observed for the pmirGLO reporter without inserted 3'UTR (NTC). The 3'UTR of AKT2 was used as a positive control, since it is a validated target of miR-184!. Effects of miR-1\$4 targeting the reporter was compared to co-transfection of reporter with cel-miR-67 (negative mimic). Data represent 3 independent experiments with triplicate measurements. P values were calculated by one sample t-test. $* \mathrm{p}<0.05 ;{ }^{*} \mathrm{P}<0.005 ; \mathrm{ns}=$ not significant; error bars display standard deviation.

Abstract THU0316 - Figure 1. in GPA nasal tissue biopsies and sera. Moreover, we screened GPA associated miRNAs for their potential to regulate proteinase-3 (PRTN3).

Methods: In an independent validation cohort (tissue and sera from 14 GPA-patients, 10 disease controls: CRS and Crohn's/CD) 12 miRNAs were examined by GPCR. Validated and computational miRNA targets were identified by mirDIP algorithms. The inhibitory capacity of miRNAs on Proteinase-3 (PRTN3) was estimated by a dual-luciferase reporter system $\left(\right.$ Promega ${ }^{\circledR}$ ). The 3'UTR-PRTN3 sequence was cloned and inserted into the pmirGlo vector and co-transfected with the hsa-mirna mimics $\left(\right.$ Dharmacon ${ }^{\circledR}$ ) into HeLa cells. As a second method, the effect of miR184 transfection on the endogenous PRTN3 expression in the human myeloid leukemia cell line HL-60 was estimated by western blot.

Results: Microarray screening revealed alterations of 24 miRNAs in GPA nasal tissue compared to $\mathrm{HC}$ and CRS. qPCR confirmed dysregulation of 6 tissue related miRNAs also in GPA sera. Compared to CD 4 miRNAs (miR-10b, -99a/100, -125b, -532-3p) were down regulated in GPA tissue. The miRNA with the highest expression level in nasal tissue from GPA was miR-184. miR-184 along with miR-708 and mir-214-5p were also predicted to target PRTN3 by the mirDIP algorithm. The dual-luciferase reporter assay revealed a significant reduction of PRTN3 expression by miR-184, while these effects could not be observed for miR-708 or miR 214-5p. The transfection of miR-184 into $\mathrm{HL}-60$ cells resulted in a dosedependent knockdown of PRTN3 expression as detected by Western blot Conclusion: Characteristic miRNA signatures in GPA, CRS and CD sug gest distinct pathophysiological mechanisms. It indicates at a local miRNA dysregulation in inflamed GPA tissue with a corresponding serum signature that might serve as novel biomarkers. To our knowledge this is the first analysis that attempts to correlate GPA-associated miRNA expression patterns in tissue with serum. Moreover, this is the first description of a miRNA (miR-184) that potentially regulates the expression of the GPA autoantigen PRTN3.

\section{REFERENCES:}

[1] O'Connell $R$ et.al. Physiological and pathological roles for microRNAs in the immune system. Nat Rev Immunol. 2010;10(2):111-122.

[2] Fasseu $\mathrm{M}$ et al. Identification of restricted subsets of mature microRNA abnormally expressed in inactive colonic mucosa of patients with inflammatory bowel disease. PLoS One. 2010 Oct 5;5(10).

[3] Neudecker, V. MicroRNAs in mucosal inflammation. J Mol Med (Berl) 2017 September; 95(9): 935-949

[4] Coit $P$ et al. An update on the role of epigenetics in systemic vasculitis. Curr Opin Rheumatol. 2018; 30(1): 4-15

Disclosure of Interests: Susanne Schinke Grant/research support from: travel and congress expenses from different companies pfizer, ucb, chemocentryx, Janssen-Cilag, msd, Nick Reichard: None declared, Barbara Russo: None declared, Antje Müller: None declared, Martin Laudien Paid instructor for: Olympus, Speakers bureau: Novartis, Robert Häsler: None declared, Gabriela Riemekasten Consultant for: Chugai, F. Hoffmann-La Roche, Speakers bureau: Chugai, F. Hoffmann-La Roche, Peter Lamprecht: None declared DOI: 10.1136/annrheumdis-2019-eular.4575

\section{THU0317 IDENTIFICATION OF ENDOTHELIAL PROTEIN C RECEPTOR AND SCAVENGER RECEPTOR CLASS B TYPE 1 AS MAJOR AUTOANTIGENS IN TAKAYASU ARTERITIS}

Tsuyoshi Shirai, Tomoyuki Mutoh, Tomonori Ishii, Hiroshi Fujii, Hideo Harigae. Tohoku University Graduate School of Medicine, Sendai, Japan

Background: Takayasu arteritis (TAK) affects the aorta and its major branches. It has been recognized that high numbers of patients with TAK possessed antiendothelial cell antibodies (AECA), which have potential to induce vascular lesion. However, their major target antigens remain unclear. The target antigens of AECA are plasma membrane proteins, and traditional methods to identify autoantigens do not differentiate between cell-surface molecules and intracellular molecules. To overcome this problem, we have developed an expression cloning system to identify cell-surface antigens: serological identification system for autoantigens using a retroviral vector and flow cytometry $(\mathrm{SARF})^{1-3}$. Because there 